\title{
Expression of 120 kilodalton protein and cytotoxicity in Helicobacter pylori
}

\author{
J E Crabtree, N Figura, J D Taylor, M Bugnoli, D Armellini, D S Tompkins
}

\begin{abstract}
Antral biopsy culture supernatants from 14 subjects with chronic gastritis, known to have IgA antibodies to the 120 kilodalton protein, showed positive recognition of this antigen in western blots against a cytotoxin positive strain of $\mathrm{Heli}$ cobacter pylori but gave negative reactions with two cytotoxin negative strains. Control immunoblots with culture supernatants from 13 non-responders to the protein were all negative. This indicates a direct association between expression of the 120 kilodalton protein in $H$ pylori strains and cytotoxicity.
\end{abstract}

Peptic ulceration in patients with chronic gastritis has recently been shown to be specifically associated with mucosal IgA recognition of a 120 kilodalton protein of Helicobacter pylori. ${ }^{1}$ Additionally, local IgA recognition of this protein is associated with the activity of the gastritis (polymorph infiltration) and epithelial surface degeneration. ${ }^{1}$ Broth culture supernatants of $H$ pylori, which have cytotoxic capacity, inducing vacuolation of cell lines in tissue culture, have recently been shown to contain a protein of similar molecular weight (128-130 kilodaltons). ${ }^{23}$ As patients with peptic ulceration are more frequently infected with cytotoxin producing strains of $H$ pylori than those with gastritis alone ${ }^{4}$ the possibility exists that the mucosal IgA recognition of the 120 kilodalton protein ${ }^{1}$ is linked to the cytotoxicity of colonising strains.

In this study the relation between 120 kilodalton antigen recognition and bacterial cytotoxin production was investigated. The mucosal IgA response of $H$ pylori positive patients known to have a 120 kilodalton antigen response ${ }^{1}$ was examined by western blotting supernatants of in vitro cultured antral biopsy specimens against $H$ pylori strains of known cytotoxin potential.

\section{Methods}

Twenty seven patients (mean (SEM) age 52.9 $(15 \cdot 8)$ ) with chronic gastritis, who had previously been shown to have a positive mucosal IgA response to $H$ pylori by western blotting, ${ }^{1}$ and four subjects with histologically normal gastric mucosa were investigated. Thirteen of the 27 patients with chronic gastritis had no IgA antibodies to the $H$ pylori 120 kilodalton protein and 14 patients had a positive IgA response.
Supernatants of three day in vitro cultured antral biopsy specimens were western blotted for $H$ pylori IgA antibodies, as previously described. ${ }^{15}$ Bacterial preparations used for western blotting were whole cell sonicates of broth cultured cytotoxin positive (CCUG 17874) and cytotoxin negative (G-21 and G-17-91) strains of $H$ pylori. Protein loading for sodium dodecyl sulphate polyacrylamide gel electrophoresis, culture supernatant dilutions, and immunoblotting conditions were identical for each strain examined. Bacterial culture and broth culture filtrate preparation were as previously described. ${ }^{4}$ Broth culture filtrates were assessed for cytotoxicity against HeLa, Vero, and $\mathrm{CHO}$ cells in vitro using the methods of Figura et al. ${ }^{4}$

Strain G-21, in addition to being cultured as above, was also grown on plates of Columbia agar with $7 \%$ horse blood, $1 \%$ Vitox (Oxoid), and the Skirrow selective supplement and used for comparative analysis with broth cultured G-21 in western blots.

\section{Results}

Patients with chronic gastritis all showed a positive mucosal IgA response to $H$ pylori in western blots using all three strains of $H$ pylori. No positive $\operatorname{IgA}$ response was observed in subjects with histologically normal antral mucosae. All the 14 patients previously defined as having a positive response to the 120 kilodalton protein ${ }^{1}$ recognised this protein in immunoblots against the cytotoxin positive strain (CCUG 17874) (fig 1A). The 120 kilodalton protein was not recognised by these 14 subjects when their culture supernatants were immunoblotted against the cytotoxin negative (G-21 and G-17-91) strains (fig 1B). These patients showed considerably reduced recognition of other $H$ pylori proteins when their culture supernatants were immunoblotted against the cytotoxin negative strains (fig 1B).

Culture supernatants of the 13 patients with chronic gastritis, previously defined as having no mucosal IgA antibodies to the 120 kilodalton protein, ${ }^{1}$ showed no recognition of this protein when immunoblotted against either the cytotoxin positive or negative strains of $H$ pylori (figs $1 \mathrm{~A}$ and $\mathrm{B}$ ). In these patients, there was considerable homogeneity in antigens recognised in immunoblots against both the cytotoxin positive and negative strains of $H$ pylori. No difference in IgA recognition of bacterial proteins in western blots of culture 
A cytotoxin +ve

(CCUG 17874)

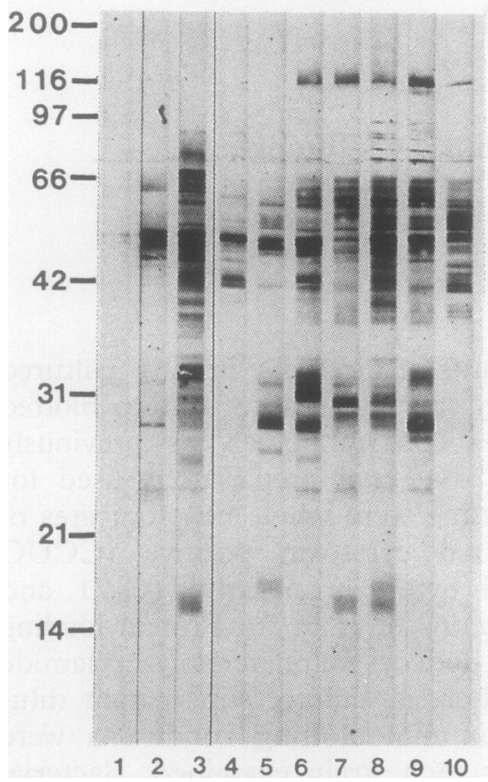

B cytotoxin -ve (G17-91)

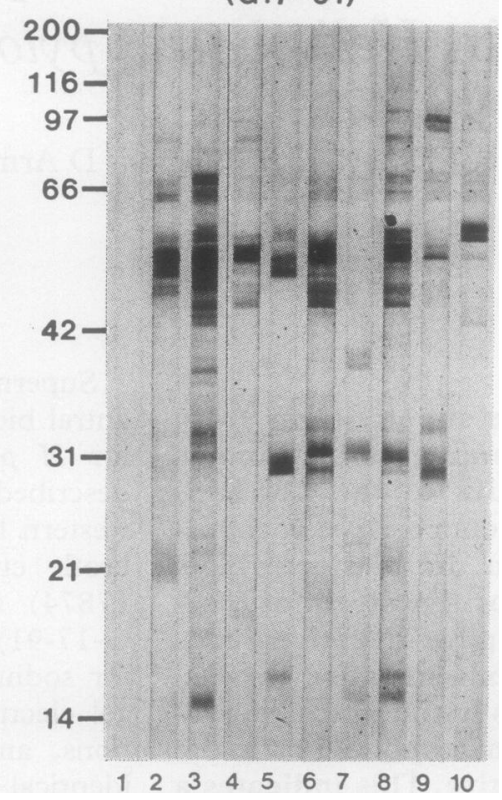

Figure 1 IgA immunoblots of gastric culture supernatants $(A)$ Cytotoxin positive $H$ pylori strain CCUG 17874. (B) Cytotoxin negative H pylori strain G-17-91. Lanes 1-10 in $A$ and $B$ are identical patients. Lane 1: control with normal gastric mucosa; lanes 2-10: patients with chronic gastritis. Lanes 2-5: no recognition of the 120 kilodalton protein. Lanes 6-10: recognition of the 120 kilodalton protein in $A$ but not in $B$. Protein molecular weight standards are given in kilodaltons.

supernatants against plate and broth grown $H$ pylori strain G-21 was apparent.

\section{Discussion}

Previous studies on systemic IgG responses to $H$ pylori have shown that patients who do not recognise the 120 kilodalton protein have no evidence of this protein in their homologous isolates. ${ }^{7}$ The association of a secretory IgA response to the 120 kilodalton protein with peptic ulceration and active gastritis suggests that strains of $H$ pylori expressing this protein are more pathogenic. ${ }^{1}$ Whether the 120 kilodalton protein is the prime factor involved in inducing pathogenicity or whether it is a marker for cytotoxicity is presently unclear.

As broth culture filtrates of $H$ pylori strains with in vitro cytotoxic potential ${ }^{346}$ contain a 128-130 kilodalton protein associated with cytotoxicity ${ }^{2}$ we considered it important to examine, by western blotting, the mucosal IgA recognition of the 120 kilodalton protein against bacterial strains of defined cytotoxic potential. Our study clearly shows that immu- nological recognition of the 120 kilodalton protein by the secretory IgA response was only evident when culture supernatants were immunoblotted against the cytotoxin positive strain of $H$ pylori. There was no recognition of the 120 kilodalton protein when cytotoxin negative strains were used as the antigen preparation. The marked reduction in recognition of other proteins by the 120 kilodalton positive patients when immunoblotted against the cytotoxic negative strains indicates considerable antigenic differences between the cytotoxin positive and negative strains. Interestingly, the patients negative for antigens to the 120 kilodalton protein showed very similar patterns of immunoreactivity in western blots irrespective of the strain used as antigen.

Recent analysis of the biotype and macromolecular profiles of cytotoxin positive and negative strains of $H$ pylori has emphasised that this bacterium is a genomically heterogeneous species. ${ }^{8}$ A close association between motility and cytotoxin production was observed in this latter study. ${ }^{8}$ Although the current study associates the recognition of the 120 kilodalton protein with bacterial cytotoxicity, further studies with purified 120 kilodalton protein are required to delineate firstly whether this protein is responsible for the in vitro cytotoxicity and secondly the relevance of this in vitro phenomenon to pathogenicity in vivo.

This study was undertaken with financial support from the Yorkshire Regional Health Authority and Glaxo plc.

1 Crabtree JE, Taylor JD Wyatt JI, et al. Mucosal IgA recognition of Helicobacter pylori $120 \mathrm{kDa}$ protein, peptic ulceration and gastric pathology. Lancet 1991;338:332-5.

2 Figura N, Bugnoli M, Guglielmetti $P$, et al. Antibodies to vacuolating toxin of Helicobacter pylori in dyspeptic patients. In: Pajares JM, ed. Helicobacter pylori, gastritis patients. In: Pajares JM, ed. Helicobacter pylori, gastritis
and peptic ulcer disease. Berlin: Springer Verlag (in press)

3 Cover TL, Dooley CP, Blaser MJ. Characterisation of and human serological response to proteins in Helicobacter pylori broth culture supernatants with vacuolising cytotoxin activity. Infect Immun 1990;58:603-10.

4 Figura N, Guglielmetti A, Rossolini A, et al. Cytotoxin production by Campylobacter pylori strains isolated from patients with peptic ulcers and from patients with chronic gastritis only. $\mathcal{F}$ Clin Microbiol 1989;27:225-6.

5 Crabtree JE, Mahony MJ, Taylor JD, Heatley RV, Littlewood JM, Tompkins DS. Immune responses to Helicobacter pylori in children with recurrent abdominal pain. $\mathcal{f}$ Clin Pathol 1991;44:768-71.

6 Leunk RD, Johnson PT, David BC, Kraft WG, Morgan DR. Cytotoxic activity in broth-culture filtrates of CampyloCytotoxic activity in broth-culture filtrates of
bacter pylori. $\mathcal{Y}$ Med Microbiol 1988;26:93-9.

7 Apel I, Jacobs E, Kist M, Bredt W. Antibody response of patients against a $120 \mathrm{kDa}$ surface protein of Campylobacter pylori. Zbl Bakt Hyg A 1988;268:271-6.

8 Owen RJ, Bickely J, Moreno M, Costas M, Morgan DR. Biotype and macromolecular profiles of cytotoxin-producing strains of Helicobacter pylori from antral gastric mucosa. FEMS Microbiol Letts 1991;79:199-204. 